\title{
The onomastic possibility of renaming the Sepedi and Sesotho sa Leboa (Northern Sotho) language names to restore peace, dignity and solidarity
}

\begin{tabular}{|c|c|}
\hline \multicolumn{2}{|c|}{$\begin{array}{l}\text { Authors: } \\
\text { Tebogo J. Rakgogo } \\
\text { Evangeline B. Zungu }^{1,2}\end{array}$} \\
\hline \multicolumn{2}{|c|}{$\begin{array}{l}\text { Affiliations: } \\
{ }^{1} \text { Department of Applied } \\
\text { Languages, Faculty of } \\
\text { Humanities, Tshwane } \\
\text { University of Technology, } \\
\text { Pretoria, South Africa }\end{array}$} \\
\hline \multicolumn{2}{|c|}{$\begin{array}{l}{ }^{2} \text { Department of African } \\
\text { Languages, Faculty of } \\
\text { Humanities, University } \\
\text { of the Witwatersrand, } \\
\text { Johannesburg, South Africa }\end{array}$} \\
\hline \multicolumn{2}{|c|}{$\begin{array}{l}\text { Corresponding author: } \\
\text { Tebogo Rakgogo, } \\
\text { rakgogotj@tut.ac.za }\end{array}$} \\
\hline \multicolumn{2}{|c|}{$\begin{array}{l}\text { Dates: } \\
\text { Received: } 23 \text { Apr. } 2020 \\
\text { Accepted: } 10 \text { Mar. } 2021 \\
\text { Published: } 26 \text { Aug. } 2021\end{array}$} \\
\hline \multicolumn{2}{|c|}{$\begin{array}{l}\text { How to cite this article: } \\
\text { Rakgogo, T.J. \& Zungu, E.B., } \\
2021 \text {, 'The onomastic } \\
\text { possibility of renaming the } \\
\text { Sepedi and Sesotho sa Leboa } \\
\text { (Northern Sotho) language } \\
\text { names to restore peace, } \\
\text { dignity and solidarity', } \\
\text { Literator } 42(1), \text { a1696. } \\
\text { https://doi.org/10.4102/lit. } \\
\text { v42i1.1696 }\end{array}$} \\
\hline \multicolumn{2}{|c|}{$\begin{array}{l}\text { Copyright: } \\
\text { (C) 2021. The Authors } \\
\text { Licensee: AOSIS. This } \\
\text { is licensed under the } \\
\text { Creative Commons } \\
\text { Attribution License. }\end{array}$} \\
\hline \multicolumn{2}{|l|}{ Read online: } \\
\hline 口ifin: & $\begin{array}{l}\text { Scan this QR } \\
\text { code with your } \\
\text { smart phone or } \\
\text { mobile device } \\
\text { to read online. }\end{array}$ \\
\hline
\end{tabular}

The study embraced the onomastic possibility of renaming the Sepedi and Sesotho sa Leboa (Northern Sotho) language names that have caused and are still causing onomastic confusion to the first language (L1) speakers of the language under scrutiny, and also to the speakers of other languages. The study was conducted in 2019 at five selected South African universities University of Johannesburg, University of South Africa, University of Limpopo, University of Venda and Tshwane University of Technology - which offered the language under investigation as an L1 module. In addition, language experts (practitioners) at the Pan South African Language Board (PanSALB) and its sub-structures and the National Department of Arts and Culture, including Limpopo and Gauteng Department of Sport, Arts, Culture and Recreation, were also involved in the study. Quota sampling was used to select all the 267 participants in the study. The study found that both Sepedi and Sesotho sa Leboa (Northern Sotho) language names are rejected by onomastic principles of naming an official language. An overwhelming majority of the participants opined that this language should be renamed, with the anticipation that the new name will bring peace, unity and solidarity to the L1 speakers of Sepedi.

Keywords: Onomastics; Sepedi, Sesotho sa Leboa; Northern Sotho; Critical Discourse Analysis; Constitution; colonial name; decoloniality and solidarity.

\section{Introduction and background}

On 18 December 1996, the South African Constitution (1996) was promulgated, after it was adopted and amended by the Constitutional Assembly on 11 October 1996. From a constitutional implementation point of view, it is important to state that Section 6 (1) of the Constitution of the Republic of South Africa (Act No. 108 of 1996) declared Sepedi as one of the 11 official languages. However, both Sepedi and Sesotho sa Leboa, which is commonly known as Northern Sotho, are perceived as one and the same official language according to this survey.

The reason behind this is that these language names are currently used extensively in informative, descriptive, policy and constitutional documentation to refer to the same official language (Rakgogo \& Van Huyssteen 2018:79). The researchers are fully aware that Sesotho sa Leboa (Northern Sotho) was only designated as one of the proposed official languages in Section 3 (1) of the Constitution of the Republic of South Africa (Act No. 200 of 1993). Therefore, the language name 'Sepedi' will in this study be used to refer to the name of the standard or official language, not Sesotho sa Leboa or Northern Sotho.

The dawn of the democratic South Africa has brought numerous changes to names (streets, cities, buildings, etc.) that were deemed to be incorrect or inappropriate. The process of changing a name is done under the supervision of the South African Geographical Names Council as it was established by the South African Geographical Names Council Act (Act No. 118 of 1998) as the body responsible for the standardisation of geographical names South Africa.

\section{The onomastic status quo on Sepedi and Sesotho sa Leboa (Northern Sotho) names}

According to Section 3 (1) of the interim Constitution of the Republic of South Africa (Act No. 200 of 1993), Sesotho sa Leboa is designated as one of the proposed 11 official languages. Subsequently, Section 6 (1) of the final Constitution of the Republic of South Africa (Act No. 108 of 1996) declared Sepedi as one of the 11 official languages. As a concomitant part of this confusion, the language in question has three different language names (Sepedi, Sesotho sa Leboa and Northern Sotho) that 
are all used in official documentation to refer to one and the same language.

Critics may argue that the onomastic controversy of language names Sepedi and Sesotho sa Leboa (Northern Sotho) to refer to one and the same official language was promulgated by the Constitution that came into effect on 18 December 1996, after it was adopted and amended by the Constitutional Assembly on 11 October 1996. This confusion is confirmed by scholars such as Mojela (1997, 1999, 2007), Kretzer (2016), Rakgogo (2016), Rakgogo and Van Huyssteen (2018), Rakgogo (2019), and Rakgogo and Van Huyssteen (2019). Furthermore, the Parliamentary Joint Constitutional Review Committee of 2011, 2016 and 2017 shared a similar view. The members of the committee criticised the replacement of the Sesotho sa Leboa name with Sepedi in the final Constitution without proper consultation with the concerned stakeholders, more particularly the first language (L1) speakers of the language under scrutiny.

As a follow-up to the Parliamentary Joint Constitutional Review Committee of 2017 titled Status of Sepedi, Sesotho sa Leboa, Khelovhedu E Sign Language of South Africa \& Khoi, Nama $\mathcal{E}$ San Languages, it is confirmed that the ad hoc committee was once instituted by the Pan South African Language Board (PanSALB) to conduct research in order to settle the onomastic dilemma of Sepedi and Sesotho sa Leboa as official names. The results showed that $64 \%$ of the tested respondents opted for Sesotho sa Leboa, 34\% of them opted for Sepedi whilst $5 \%$ of them were uncertain. Thus, it can be gathered that Sesotho sa Leboa is indeed the language name which is more appropriate and inclusive, according to the L1 speakers of the language under scrutiny.

In a Parliamentary Joint Constitutional Review Committee of 2020, Prof. Lotriet asked if Ms Sipamla could provide an update on the issue of Sepedi and Sesotho sa Leboa which was also raised in 2017. In her response, Ms Sipamla addressed the question on why Sesotho sa Leboa was not referenced as an issue that had come through to the Committee previously. It was pointed out that there was a difference of opinion on whether Northern Sotho or Sepedi should be reflected in the Constitution. It was further asserted that Sepedi was incorrectly reflected and that Sesotho sa Leboa (Northern Sotho) should be reflected instead. It was not a matter that submitters were requesting for official language status, but rather the submitters had requested that their language be reflected as Northern Sotho instead of Sepedi. The Committee consulted extensively at that time and the experts advised that in the Sepedi version of the Constitution, the language is reflected correctly whereas in the English version of the Constitution, it is reflected in a different way.

It was articulated that the current state of affairs on the onomastic dilemma of the language names has divided the speakers of the language in question into two groups. One group has accepted Sepedi as an official language whilst the other has rejected Sepedi as an official language. It is germane to articulate that both groups are onomastically fighting for the recognition of their chosen language name in the South African Constitution. In this study, the views of the two groups on the renaming of the language under scrutiny will be thoroughly put into perspective.

\section{Research problem}

The official language name Sepedi, as mentioned in the Constitution of South Africa (1996), has divided L1 speakers into two groups. One group is in support of the Sepedi name and the other is rejecting the name. Up to now, there have been numerous surveys and parliamentary discussions on the official name of the language in question. In all the surveys that have been conducted on Sepedi and Sesotho sa Leboa (Northern Sotho), the majority of the respondents and participants were in support of Sesotho sa Leboa (Northern Sotho) as the name suitable to be included in Section 6 (1) of the Constitution. In justification of the chosen language name, it was argued that Sepedi is a dialect, not a language. Others cogently argued that the process of replacing the name Sesotho sa Leboa with the name Sepedi was not consultative and transparent. On the other hand, those who support Sepedi as the rightful name to be maintained in the Constitution argued that Sesotho sa Leboa (Northern Sotho) is a colonial name.

Therefore, they cannot identify themselves with the name that was created by the coloniser. It needs to be mentioned that the problem that initiated this study is the name that is attached to the official language, not the language per se. The above-mentioned two groups are fighting over a language name.

In this onomastic study, the authors point out that the views of the minority group on this issue cannot be ignored and undermined. Furthermore, the views of those in support of neither Sepedi nor Sesotho sa Leboa should also be taken into consideration to ensure that there is peace, unity and solidarity amongst the speakers of this language. It is argued that these three aspects, peace, unity and solidarity, may be achieved through a language name. It is for this reason that the study aims to investigate the possibility of renaming the language under onomastic scrutiny in order to restore the dignity and identity which were tarnished by the use of different language names to refer to one and the same language. Based on observations, Sepedi and Sesotho sa Leboa (Northern Sotho) language names are often used interchangeably, but they are not considered synonyms. This is mostly done by the speakers of the other languages who are not following politics surrounding the above-mentioned names as two different ones. Based on this submission, it is arguable that Sepedi and Sesotho sa Leboa (Northern Sotho) mean different things to different people. 
In encapsulation of the above-stated problem, the authors emphasise that the limitation of this article is the inconsistent use of Sepedi and Sesotho sa Leboa (Northern Sotho) as official names. Whilst Section 6 (1) of the Constitution of South Africa cites Sepedi as one of the 11 official languages, in this study, we argue that the constant use of the name Sesotho sa Leboa (Northern Sotho) in informative, descriptive and policy documentation validates that there is strong opposition to the official 'Sepedi' language name. This article argues that change in the name of a language may have a direct effect in enhancing social cohesion amongst the L1 speakers of the language under onomastic scrutiny.

\section{Objectives of the study}

Based on the foregoing state of the onomastic problem surrounded by a lot of controversies, the objectives of the study were to:

- investigate the possibility of renaming the Sepedi and Sesotho sa Leboa (Northern Sotho) language names

- determine whether the new language name has the potential of bringing peace, dignity and solidarity amongst L1 speakers of the language in question

- use Sepedi and Sesotho sa Leboa (Northern Sotho) language names as a way of interrogating diverse issues that touch on naming, power, politics and history.

\section{Critical discourse analysis as a theoretical framework that underpins the study}

In onomastics, it is reasonable to argue that most names are given by those in power and the selected or chosen names may also in most cases reflect the wishes of those in power. This is why scholars such as Van Dijk (1995:20) postulate that discourse is all about the expression of social power, position, status, dominance, culture, politics and race. Critics may reason that the issue of social power, influence of politics and the current status of Sepedi as one of the 11 official languages in Section 6 (1) of the Constitution of South Africa is what gave birth to the onomastic controversy of Sepedi and Sesotho sa Leboa (Northern Sotho) as one and the same language name. The reason for this is that the Sesotho sa Leboa (Northern Sotho) language name which appeared in the interim Constitution of 1993 was replaced with the Sepedi name in the final version of the Constitution, 1996, without a transparent and consultative process.

Wodak (2001) shares a similar perspective with Van Dijk (1995) when asserting that powerful groups abuse power unless the powerless groups decide to resist. It is against this background that the speakers of the language in question are divided into two groups. The one group is advocating for the replacement of the Sepedi name with the Sesotho sa Leboa (Northern Sotho) name because the name Sepedi is highly associated with the Sekhukhune ethnic group (Rakgogo 2016:109-110). The L1 speakers argued that the language name Sepedi is more exclusive than Sesotho sa Leboa (Northern Sotho). In terms of discourse analysis, it can be argued that the Sekhukhune ethnic group is perceived to be more dominant, influential and powerful than other ethnic groups such as Balobedu, Batlokwa, Baphalaborwa, Bapulana, Bahananwa, etc.

Critical discourse analysis as a method of analysing data and making sense of data is relevant for this kind of onomastic inquiry. The reason behind this is that the focus is on the use and misuse of power (political or ethnic) in expressing and taking decisions about language and naming issues.

\section{What is onomastics?}

Generally, the term onomastics or onomatology may be interpreted and understood as the study of proper names of all kinds and their origins. These proper names may include language names, geographical names, place names, street names, personal names and animal names. In this study, the proper names that will be given attention are the names Sepedi and Sesotho sa Leboa.

Koopman (2002) as one of the leading scholars of onomastics in Southern Africa explains that the word 'onomastics' is derived from the Greek word onoma which means 'name'. He further cogently mentions that onomastics is:

$[T]$ he study of names and naming systems. In any language, names are nouns, in the word category of proper nouns or proper names. As names are linguistic units which normally operate within a social context, onomastics can be considered as a branch of sociolinguistics. (p. 8)

Machaba (2004) observes and provides another comprehensive definition of the term onomastics. She defines onomastics as:

[A] branch of sociolinguistics that comprises naming, renaming and denaming of entities. Onomastics as a study, goes beyond looking at the linguistic features of names, but also looks at the sociocultural and psychological factors that influence the choice of a name given to an entity by the namer. (p. 25)

The authors of this article agree with Machaba (2004) that renaming a particular entity, language, city, street etc. is part of the onomastic processes. It is thus clear that the above definition links directly with the main objective of the current study because the focus is on renaming the Sepedi language as Sesotho sa Leboa (Northern Sotho).

\section{The onomastic theory on the process of changing the name}

Manatsha (2014:275) attests that language is a powerful tool in the politics of street and language naming. The use of Hebrew, English or Arabic in street, place, language, etc. in Israel entities has an ideological and political significance because naming streets is perceived as an expression of power and authority. In this study, it can be understood 
that the use of the English language in naming an African indigenous language (Northern Sotho) is a true reflection of what Manatsha is postulating. This kind of onomastic exercise proves the powers of the colonisers on the colonised.

With regard to the issue of changing the name, the South African Geographical Names Council was established by the South African Geographical Names Council Act (Act No. 118 of 1998) as the professional and competent body responsible for the standardisation of geographical names and also the names of public entities in South Africa. In this quest, one may notice that the onomastic dilemma that initiated this study can be resolved if the matter were to be brought under the jurisdiction of the afore-mentioned council for proper investigation and onomastic scrutiny.

In contemporary South Africa, like other countries on the African continent, there have been several onomastic changes and it is quite interesting to observe that it is still a continuous process. According to Ndletyana (2012:87), the new guidelines by the South African Geographical Names Council are aimed at eliminating duplication, rectifying orthographic errors, according official recognition to place names commonly used by residents and sensitising toponyms to South African democratic values and diverse history. By having a closer look at the above-mentioned onomastic factors, it is overwhelming to note that name duplication is one of the qualitative variables associated with changing the name. In this study, the issue that is surrounded by onomastic controversy is the use of both Sepedi and Sesotho sa Leboa (Northern Sotho) as language names referring to one and the same language. Thus, it can be stated that the official language names investigated in this study meet the guidelines and requirements provided by the South African Geographical Names Council.

Kadmon (2013:86) submits that a politically motivated name replacement can be found in any region that suffered from administrative instability, especially from changes in local regimes. Similarly, Manatsha (2014:275) supports that the process of renaming places, languages, streets and other public entities will remain an ongoing exercise as long as there are social and political 'revolutions'.

Ndletyana (2012:86) affirms that the renaming process is primarily a function of different ways in which the black population relates to colonial memory. Some will identify with it, whilst others may be ambivalent.

In the context of the language under onomastic investigation, it is evident that the L1 speakers of this language are divided into two groups. Some identify themselves as Bapedi (Sepedi speakers), of which Sepedi is considered a dialect by most of the speakers. On the other hand, others identify themselves as Basotho ba Leboa (Northern Sotho speakers), the name of which is considered a colonial name by some of the speakers.

\section{Colonial influence on the language names of the colonised}

The Republic of South Africa, like other countries on the African continent, was once ruled by the colonisers who influenced and implemented the western culture of naming, with the main purpose of entrenching the previous regime (Apartheid regime). In support of this view, Mandende (2009:1-2) explains that the history of the African continent has been marked by colonisation because when the Europeans first arrived in Africa, they brought with them their cultural values and they sought to ensure that the indigenous people of this continent abandon their cultural systems and follow the cultural systems of their new masters, even if this was against the indigenous people's wishes. He maintains that one of the systems most severely affected as a result of colonialism was the way in which proper names (personal names, language names, etc.) were selected and bestowed.

Focusing strictly on African languages, Makoni et al. (2005:135) add that in some cases, even the proper names given to some of the African languages and speech forms were invented by the Europeans. Sharing a similar perspective with Mandende (2009), Mashige (2004) and Makoni et al. (2005), Manatsha (2014:272) laments that colonialism played a major role in 'erasing' the identities of the conquered and colonised communities in many ways. For example, the colonialists got rid of the indigenous or local names of many places, languages, etc. They replaced these names with names that represented the coloniser's identities.

Concerning the issue of naming and identity, Harder (1986) in Rakgogo (2019:156) as one of the most vocal advocates of the relationship between naming and identity cogently articulates that names should not hamper the correct identification of a human being. In addition to this, Joseph (2004) in Pfukwa (2007:42) similarly observes that being named is an 'enacted identity'. He further argues that naming oneself can be perceived as an act of self-perception, selfconcept or self-praise. Furthermore, it can be onomastically justified that the meaning attached to names by Basotho plays a significant role in the definition of personhood; it is believed that a given name not only serves as an identity but also determines the type of person the individual will be (Mthobeli 2001 in Rakgogo 2019:157).

It is against this background that Mashige (2004:8-9) supports calls made by theorists such as Ngugi wa Thiong'o for a 'return-to-the-roots'. The implication of this return includes the total rejection of any traces of colonial culture and traditions in the quest to forge what wa Thiong'o calls an authentic African cultural regeneration, national pride and unity. When the researchers take into consideration the work of Ngugi wa Thiong'o, it can be reasoned that all the names that were created in order to suit the administrative reasons of the colonisers should be rejected in order to restore unity and pride of the authentic African culture and traditions. 
Therefore, in this study, should both Sepedi and Sesotho sa Leboa (Northern Sotho) language names be linked with the influence of colonialism, they deserve to be rejected in order to align with what Ngugi wa Thiong'o has suggested.

\section{The onomastic principles of naming a language}

Harder (1986) in Rakgogo (2019:85-89) lists the following as the principles that should be taken into consideration when naming a language:

- Names should be suggested by insiders.

According to this principle, it is clear that the L1 speakers of the language should be the name-giver of their own language. In this article, Sesotho sa Leboa (Northern Sotho) language name is found to be questionable, because the literature consulted proves that this name has been influenced by the colonialists. Sesotho sa Leboa (Northern Sotho) is considered an instructive name that was imposed on the people without proper consultation. It is for this reason that scholars such as Mesthrie (2002) in Rakgogo (2019:111-113) state that the indeterminacy of naming Northern Sotho, Southern Sotho and Western Sotho was instructive.

- After preliminary screening, the results should be tested on a variety of people before implementation.

This principle touches on the importance of transparency and consultation before a particular name can be officialised. In the problem statement of this article, the replacement of Sesotho sa Leboa (Northern Sotho) by Sepedi in the final Constitution (1996) without consultation with the L1 speakers is considered as one of the contributing factors why the two mentioned language names caused divisions amongst the speakers of the language.

- Names should not have different meanings to different people.

Sepedi and Sesotho sa Leboa (Northern Sotho) are presently perceived as two different language names that are both used to refer to one and the same official language. However, the names in practice mean different things to the L1 speakers of the language under investigation. The literature consulted in this article pronounces that some of the L1 speakers view Sepedi as the rightful name to be maintained in Section 6 (1) of the South African Constitution whilst other speakers view Sepedi as one of the dialects, which it is inaccurate to include as one of the 11 official languages of South Africa. According to these speakers, Sepedi is just a dialect and it should remain like that. Sesotho sa Leboa (Northern Sotho) is the correct name that should be declared officially in the African Constitution.

It is argued that the naming of the language in question was not done according to this principle. The reason for this is that the two names that caused and are still causing onomastic controversy are completely understood as two different names that do not mean one thing. It can, therefore, be concluded that the above-mentioned principle rejects
Sepedi and Sesotho sa Leboa (Northern Sotho) as language names that should be attached to the standard official language.

\section{Research design}

The research design selected for the present investigation involved a triangulation mixed methods approach in which both quantitative and qualitative instruments for data collection and analysis were used. Ivankova, Creswell and Plano Clark (2016:266) note appropriately that the name triangulation comes from the same term used in surveying and in ship navigation when multiple measurements are used to provide the best estimates of the location at a specific point (like the point at the top of a triangle). In this article, interviews, questionnaires and observations were used as the three focal points that form a triangle.

\section{Research approach}

The research employed the mixed-methods approach in order to achieve the aims and objectives of the study. In essence, both qualitative and quantitative methods were combined.

\section{Sample population of the study}

The sample population of this study consisted of 267 participants, but only 265 participants were strictly considered the L1 speakers of Sepedi. A large number of participants were undergraduate and postgraduate students from five selected South African universities (University of Johannesburg, University of the Witwatersrand, University of South Africa, University of Venda and Tshwane University of Technology) that offer Sepedi as an L1 and Applied Language module. The lecturers who teach the module at all the selected universities were also taken into consideration. Language experts from PanSALB and its sub-structures and the National Department of Arts and Culture, including the Limpopo and Gauteng Department of Sport, Arts, Culture and Recreation, were also involved. In addition, six traditional leaders from some of the district municipalities (Mopani, Capricorn, Sekhukhune and Waterberg) where the language under research is spoken were also invited to participate in the study.

In this study, students and lecturers from all the South African universities that are offering the language under scrutiny (Sepedi) as an L1 or Applied Language module were targeted as the major participants. The rationale for this inclusion is that they are mostly victims of the onomastic discrepancy of the Sepedi and Sesotho sa Leboa (Northern Sotho) language names in the official documentation. One of the major contributing factors why the researchers perceive them as the major participants is that they are studying or learning this language as an L1 or Applied Language module at the university level, which can be associated with a positive attitude towards the language. It also needs to be mentioned that students and lecturers belong to different 
ethnic groups and they speak different dialects, wherein the understanding is that they also represent the speech communities that they originally come from. Lastly, because they are teaching and learning the language under onomastic scrutiny, it is believed that some of them have already started to research, write and publish about this language. PanSALB and its substructures are constitutionally mandated to develop, promote and protect South African languages. Therefore, its inclusion in the sample was relevant because the article touches on status type of language planning. ${ }^{1}$

\section{Methods of data collection and analysis}

In this study, survey questionnaires consisted of closeended and open-ended questions, semi-structured interviews and observations were used as methods of quantitative and qualitative data gathering. Furthermore, text analyses using Parliamentary Joint Constitutional Review Committee minutes as primary sources were also used. Policy documentation and South African Constitutions (interim and final), including the translated versions of the Constitution, were also employed and classified as internal documents. The reason for this kind of an inclusion was to supplement the other methods of data collection.

As for data analysis, the main researcher used an Excel spreadsheet to capture the quantitative data gathered from the close-ended questions and data were, therefore, analysed numerically and statistically by the professional statistician. Graphs and pie charts were also used in order to easily show the quantitative figures which were at a later stage accompanied with the qualitative responses. In the case of open-ended questions, the researcher then used descriptive analysis to analyse the collected data. For interviews, the study was purely guided by an interpretive paradigm. The transcripts were listened to attentively with the aim of gaining a general understanding of each and every perspective. Thereafter, thematic analysis was applied in order to come up with the qualitative themes which encapsulate the responses from the participants.

\section{Analysis of Section B of the survey questionnaire: A Likert scale questionnaire}

The respondents in this section were requested to carefully read the statements below in order to select the statement that best represents their opinions, by making a cross $(X)$ in the appropriate block according to the following five key options: (1) strongly disagree; (2) disagree; (3) not sure; (4) agree or (5) strongly agree. The choices of the total sample population of 260 respondents were collated and expressed as means to determine the participants' attitudinal positional tendencies. In total, the Likert scale type of questionnaire used in this study comprised 17 statements which were

1.A great limitation of this article was not involving speakers of the language who are at grass roots level (elders, church leaders and general members of the community). Furthermore, the study also excluded high school learners, language educators and older community members in general. It would be interesting to gather an onomastic and a sociolinguistic perspective of all the L1 speakers of the Northern Sotho language about the viewpoints regarding the naming of Sepedi and Sesotho Sotho language about the vien
sa Leboa (Northern Sotho). purely contextualised on the importance of naming in the South African context.

Statement 1 (Table 1) recorded a higher mean score of 4.5 which shows that participants strongly agreed. The participants in this regard are of the same opinion that the naming of entities (languages, cities, streets, etc.) should not be associated with politics; it should be a purely linguistic act. It was earlier indicated that in this study, naming is an onomastic exercise that sometimes tends to be manipulated by the influence and power of politics so that it can be easier for people to become subjugated.

Still on the influence of power and politics in name and language designation, Statement 2 (Table 2) recorded a mean score of 4.0 and shows an attitudinal tendency to agree. The interpretation of this mean score is that the participants in this onomastic study have the idea that the language name discrepancy that can be realised in Section 3 (1) of the interim (1993) and Section 6 (1) of the final (1996) Constitutions of South Africa was a purely political exercise. In terms of this study, it is important to understand that a similar conception was earlier mentioned under the problem statement of the study, wherein the process of replacing the Sesotho sa Leboa name with the Sepedi language name lacked transparency, as it was done without proper consultation with the relevant stakeholders.

Statement 3 (Table 3) recorded a high mean score of 4.7 which indicates that participants strongly agreed. It is alarming to notice that the L1 speakers of this language, who also registered or completed the language under scrutiny as a first or applied language module, are of the view that the onomastic dilemma surrounding Sepedi and Sesotho sa Leboa names will not end any time soon, just because of ethnic pride and the misuse of political powers.

Touching on the onomastic principles of naming a language, the participants in this study responded with a mean score of 4.6 (Table 4) which shows that the L1 speakers strongly agreed. In a more practical sense, they concur that a language name should be specific and should also be free from confusion and politics. It is, however, not known at this stage as to which language name between Sepedi and Sesotho sa Leboa (Northern Sotho) seems to be more specific and not associated with confusion and politics.

TABLE 1: Statement 1 (S1).

\begin{tabular}{lc}
\hline Statement & Mean \\
\hline $\begin{array}{l}\text { 1. Naming an object, person, place, street or language should be treated } \\
\text { as a linguistic act all the time, not a political one }\end{array}$ & 4.5 \\
\hline
\end{tabular}

TABLE 2: Statement 2 (S2).

\begin{tabular}{lc|}
\hline Statement & Mean \\
\hline $\begin{array}{l}\text { 2. The replacement of Sesotho sa Leboa in the interim constitution (1993) } \\
\text { with Sepedi in the final constitution (1996) of the Republic of South }\end{array}$ & 4.0 \\
\hline
\end{tabular}

Africa (1996) was politically motivated 
A significant majority of the participants on Statement 5 (Table 5) agreed that both Sepedi and Sesotho sa Leboa should be replaced with a new neutral name that cannot be associated with any dialectal classification or the Apartheid regime. This was after a high mean score of 4.6 was reached which shows that participants agreed and inclined towards strongly agree.

It is interesting to note that there seems to be a consistent response to these statements. The rationale behind this is that earlier in Statement 4, the participants strongly agreed that the onomastic controversy surrounding Sepedi and Sesotho sa Leboa language names will not end any time soon because of ethnic pride within the speech communities of the language under investigation.

\section{Presentation and discussion of the qualitative data}

RQ1: Do you consider a language name as an essential aspect in society? Motivate your answer by indicating the relationship between speech community and a language

This question was both closed and open-ended. Focusing on the closed-ended part, a significant majority (96\%) of the participants responded that they considered a language name as an important aspect in society whilst $4 \%$ of the participants were of the opposite view and posited that the language name is less important in society as clearly demonstrated in the pie chart shown in Figure 1.

Those participants who opined that a language name is an important aspect in society indicated that names in general are as important as language and that if there were no languages, then that language name was going to be regarded as something that is not important. In support of this, P238 mentioned:

'[A] language name identifies and unifies communities that speak different dialects, but belong to one historical background. For example, Bapedi (for Sepedi speak a "principal" dialect and can be linguistically grouped together with the Balobedu, Batlokwa, Bapulana etc.' (P238)

To add to this, P236 shared that:

TABLE 3: Statement 3 (S3).

\begin{tabular}{lc}
\hline Statement & Mean \\
\hline $\begin{array}{l}\text { 3. The onomastic controversy surrounding the Sepedi and Sesotho sa } \\
\text { Leboa languages names designating the same language will not end } \\
\text { any time soon due to ethnic pride and misuse of political powers }\end{array}$ & 4.7 \\
\hline
\end{tabular}

TABLE 4: Statement 4 (S4).

\begin{tabular}{lc}
\hline Statement & Mean \\
\hline $\begin{array}{l}\text { 4. The name of the language should be specific enough, free from } \\
\text { confusion and politics }\end{array}$ & 4.6 \\
\hline
\end{tabular}

TABLE 5: Statement 5 (S5).

\begin{tabular}{lc}
\hline Statement & Mean \\
\hline $\begin{array}{l}\text { 5. Due to ethnic pride and dialectal classification, both names } \\
\text { (Sepedi and Sesotho sa Leboa) should be replaced with a new neutral }\end{array}$ & 4.6 \\
name that cannot be associated with any dialect or the previous & \\
government (Nationalist Party) & \\
\hline
\end{tabular}

'[L]anguage naming is a very important aspect since it emphasises the identity and culture of the community.' (P236)

Having noted that the quoted participants touched on the issue of identity, it needs to be mentioned that the relationship between language naming and identity cannot be separated and that the three are onomastically and sociolinguistically bound.

Representing $4 \%$ of the participants who were of the view that a language name is not important in society, P9 in this case argued that:

'[T]he Northern Sotho speech community lives with many different names (languages) of which some are meaningless, but there are no reasons why they go along with such incorrect identification of a particular speech community. For example, I am Motlokwa but I am constitutionally regarded as Mopedi and all my friends address me as Motlokwa. Why do I not suffer the consequences of being addressed with my dialectal name?' (P9)

This Participant (9) in this regard mentioned an important point which also needs to be taken into consideration. This view will, however, be given less attention because the majority already indicated that the issue of dual naming tarnishes their identity.

\section{RQ2: Is naming important? If so, explain the importance of naming in an African context.}

As the current study can be characterised by diverse onomastic tensions, this question was consciously linked with the first research question. The rationale behind this is that the main researcher wanted to observe whether the participants maintain consistency and uniformity when responding to the research questions. It needs to be highlighted that this kind of repetition will subsequently help in determining the validity and reliability of current onomastic research. Surprisingly, $97 \%$ of the participants mentioned that naming is important with African societies at large. On the other hand, it is only $3 \%$ of the participants who held a different ideology that naming is considered an unimportant aspect, especially in the context of Africa as shown in Figure 2.

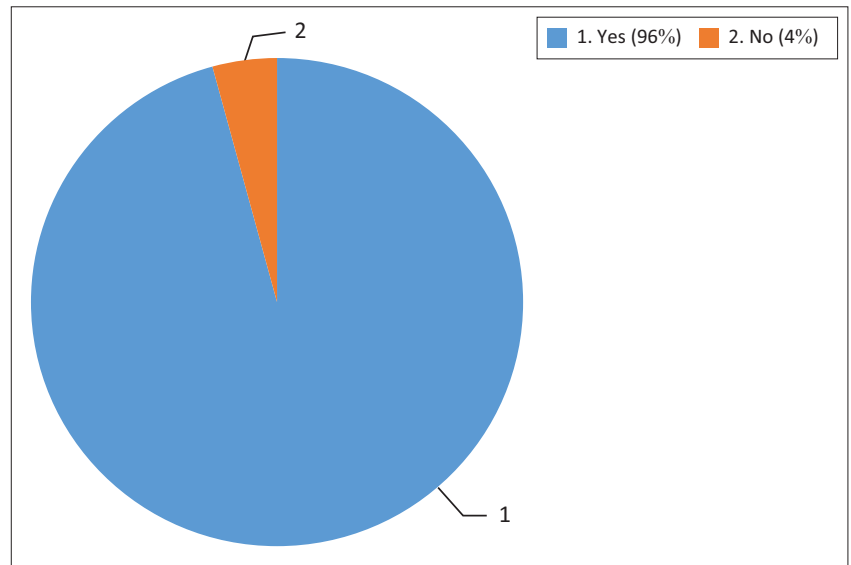

FIGURE 1: The importance of a language name in a society. 
It has been argued by different scholars in the field of onomastics and sociolinguistics that naming within African cultures is strictly considered a linguistic act which should not be underestimated. In directly quoting those participants who perceive naming as an important practice in African societies, P71 in this regard argued:

' $[I] \mathrm{f}$ we are to be specific, we need to name as not all things are abstract. Languages vary and so the name identifies the speaker and culture within the history of the original speakers.' (P71)

\section{Sharing a similar conception, P80 added that:}

'[N]aming is seen as a symbol of identity in an African context. It is further understood as a symbol of cultural pride, since it carries cultural and historical significance.' (P80)

What was articulated by $\mathrm{P} 80$ about identity and naming forms a very crucial train of thought in this study. The reason for this is that one of the research questions elaborates on the participants' revelations with regard to whether they accept Sepedi as a symbol of identity. It is, however, important to mention that the mentioned Participant (80) accentuated that naming in an African culture is considered a symbol of identity.

Another Participant (69) put forward another critical conception that:

'[N]aming can be used as a linguistic weapon of conveying and preserving certain messages. Naming of languages, people and places within the African continent have certain elements of culture and history attached to them. Certain names can tell a bit of a history - be it a political, social or religious background.' (P69)

What this participant has just proposed is supported by onomastics scholars such as Mandende (2009) as he pointed out that naming within the African continent was mainly used to document historical events, before people were able to read and write.

\section{RQ3: Do you associate the onomastic controversy of Sepedi and Sesotho sa Leboa language names with influence of power and politics? Motivate your answer}

A significant majority (71\%) of the participants in this context mentioned that they associate the politics surrounding

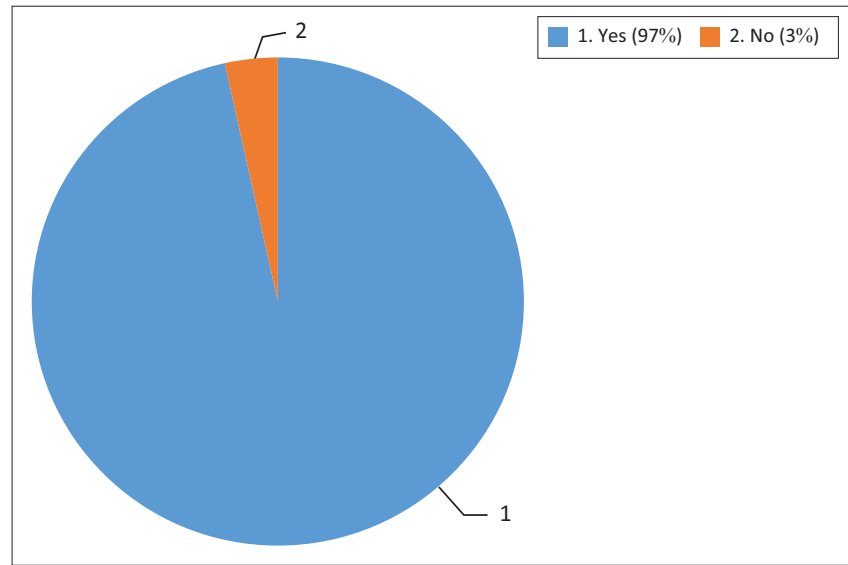

FIGURE 2: The importance of naming.
Sepedi and Sesotho sa Leboa names with the influence of power and politics. On the other hand, $29 \%$ of the participants held a different perspective and they opined that the controversy surrounding these names has nothing to do with power and politics as shown in Figure 3.

Both participants in favour of Sepedi as well as the ones in favour of Sesotho sa Leboa were in the majority and shared a similar perspective. Many scholars in the field of language planning and standardisation argue that languages have always been politicised and used to entrench the ruling regimes. In this study, $71 \%$ of the participants shared a similar point of view with what the scientific scholars have observed when it comes to language issues in many countries, including South Africa.

\section{In this regard, P176 revealed that:}

'[S]outh Africa is a very good example when it comes to the influence of power and politics on language issues. For example, a study like this was initiated by the misuse of power in politics when the Apartheid regime divided the languages to Northern Sotho, Southern Sotho and Western Sotho. The division created by colonialism has caused so many divisions that it could never be resolved, since some of the speakers of the Sepedi language still perpetuate and promote names that were imposed on them. In my humble opinion, the controversy that you are investigating originated from petty tribalistic politics coupled with power hunger aimed at achieving a personal, greedy goal.' (P176)

Another participant added that:

'[T] he naming of the official language as "Sepedi" was influenced by the power of politics. This kind of decision was purely motivated by economic and political powers, since the Sekhukhune people were perceived as a powerful ethnic group. I think you as a researcher should also try to check the background of the people who were involved when the language was named "Sepedi." You could find out that representatives from the other dialects were not included in that committee as they are perceived as inferior.' (P16)

Commenting on the missionaries' role, P6 stated that:

'[T]o some extent, when the German missionaries started with the recording and naming of the Sepedi language, it was just for

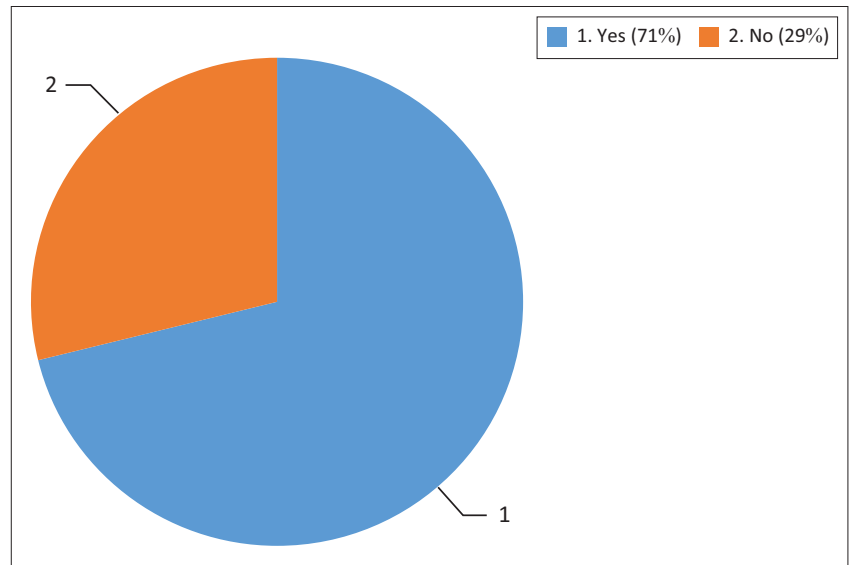

FIGURE 3: Sepedi and Sesotho sa Leboa names vis-à-vis power and politics. 
self-identification purposes, but now speakers of Sepedi have by default assumed undue power and status which they did not earn. On top of this, the fact that ordinary speakers of the language were not involved in the decision-making process regarding the standardisation of the language shows that power and politics are at play.' (P6)

The quoted participants shared balanced criticism. Others criticised one-sided standardisation that gave only Sepedi official recognition whilst a few others criticised the influence of colonialism on this language that gave birth to concepts such as Northern Sotho, Southern Sotho and Western Sotho. It is quite impressive to record that according to the participants who were also the L1 speakers of this language, both language names are not free from power and politics.

In terms of this study, one may realise that the sociolinguistic history of the language under investigation as also revealed by the participants is heavily marked by the influence of power and politics. The researchers, therefore, submit that in contemporary South Africa, the most telling example of the influence of power and politics on language issues can be detected from the replacement of Sesotho sa Leboa with Sepedi in the final Constitution without proper and transparent justifications.

\section{RQ4: From a constitutional implementation point of view, do you think the replacement of Sesotho sa Leboa with Sepedi in the final Constitution compounds the problem of this onomastic dilemma? Justify your answer}

As argued earlier, the researchers claimed that the language name discrepancy that can be detected in Section 3 (1) of the interim and Section 6 (1) of the final Constitution of South Africa compounded the main problem of the current study. This question aimed at testing the knowledge of the participants on the sensitive onomastic issues that are under investigation.

To this research question, $52 \%$ of the participants were of the view that the South African Constitution is perceived as a major contributing factor in the onomastic politics of the Sepedi and Sesotho sa Leboa language names as one and the same. On the other hand, $48 \%$ of the participants were of the opposite view that this has nothing to do with the Constitution as shown in Figure 4.

Noting that the difference is only $2 \%$, this suggests that the participants held completely different ideologies on what should be considered the initiator of the Sepedi and Sesotho sa Leboa (Northern Sotho) onomastic controversy. Starting with the majority, P215 said that:

' $[T]$ he Consitution compounded and is still compounding the problem because at the moment, the linguistic community is divided about the language name. Some regard themselves as superior to others while some regard themselves as inferior as their dialects are considered inferior. The amazing part is that there are no practical meusures in addressing the problem, especially from the constitution's point of view.' (P215)
In addition to what P215 articulated, P75 outlined that:

'[T] he current onomastic dilemma is attributed to the use of Sepedi as a language name that represents all the multiple dialects that are spoken in most parts of the Limpopo province. This is the problem that was identified by the real speakers of these dialects as they needed this to be corrected. They proposed that Northern Sotho should be the final name that represents all the dialects.' (P75)

With reference to the views of those participants who blame the Constitution, P227 in this regard argued that:

'[T] he language belongs to the people who speak it, not those who take decisions about it. Up to so far, there is no one who can give you a valid reason as to why Sesotho sa Leboa was replaced with Sepedi in the final version of the Constitution. All that they know is to be defensive even though they can't even write a mere academic paper on those reasons, just because they know that they do not have a case. The main question for me is why were the speakers of the language not included in that decision?' (P227)

Giving the above excerpts a closer look, it can be noted that their argument sounds valid and legitimate, especially within the context of three important things that form an important part of the current study. These are but not limited to the:

- lack of consultation with the first language speakers when the language name was changed in the final Constitution

- lack of practical measures from the Constitution

- Sesotho sa Leboa manages ethnic pride that is escalated by automatic elevation of the name of a particular dialect to the status of an official language name.

Because $48 \%$ of the participants held a different perspective that the controversy of Sepedi and Sesotho sa Leboa cannot be associated with the South African Constitution, P34 in this case argued that:

'[T] he fundamental purpose of the supreme law (Constitution) of any country is to nullify any form of irregularity. The speakers of the language under onomastic research must understand that any law, the Constitution inclusive, is a judicial instrument designed to guage and balance the probabilities.' (P34)

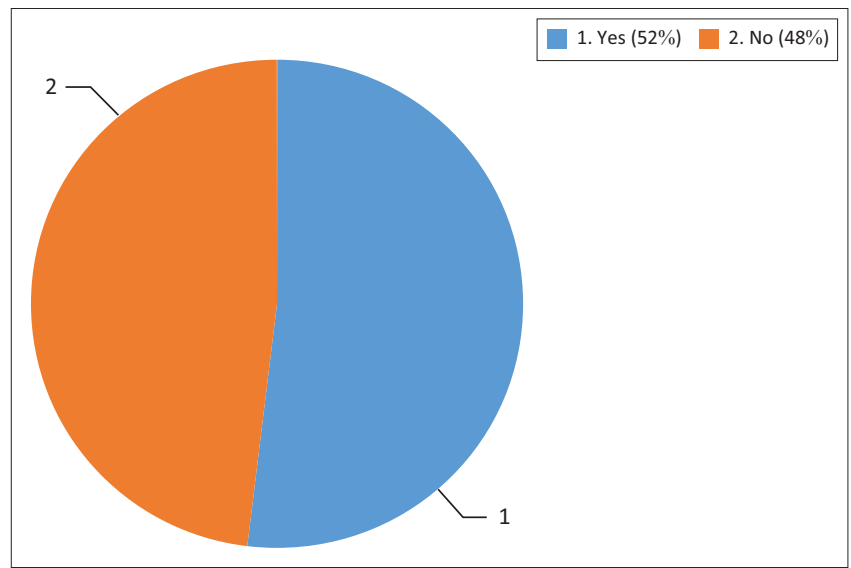

FIGURE 4: The role played by the South African Constitution (1996). 
From an onomastic perspective, P91 stated that:

'[T]he politics surrounding Sepedi and Northern Sotho (Sesotho sa Leboa) did not start in 1993 and 1996, there has always been an onomastic dilemma of these two language names and these were never academically investigated. For example, there are so many books that were published in this language, but their cover pages indicate different language names. These were due to the colonialism mandate of eradicating African, language names and bestow ones that suit the western culture and its adminstration.' (P91)

Sharing a similar view, P236 shared that:

‘ $[T]$ he replacement was only in the finalisation process and there is absolutely nothing wrong with changing a name that was incorrectly included in the first draft. What is wrong with changing when finalising? Political progressiveness would also encourage doing away with the descriptive nature of naming by the previous regime. There was a need to relook into the inclusion of Sesotho sa Leboa as it has strong ties with the Apartheid regime.' (P236)

Both P91 and P236 in this context argued that the Constitution of the Republic of South Africa (1996) did the right thing by removing the Sesotho sa Leboa name because it came from the Apartheid regime. It is quite fascinating to observe that their interpretation is also captured in the conducted literature review. In contemporary South Africa, it is against this background that the current regime in consultation with the relevant stakeholders is working together with the aim of reversing the onomastic subjugation that was a concomitant part of colonialism.

RQ5: From a constitutional implementation point of view, if Sesetho sa Leboa were to replace Sepedi in the South African constitution, would the present debate surrounding these names be resolved? Justify your answer

Because the controversy under onomastic investigation touches on the South African Constitution (both interim and final), the researchers assumed that this kind of question may help much in resolving the matter. When responding to this question, $93 \%$ of the participants shared the view that the matter will not be resolved by replacing Sepedi with Sesotho sa Leboa in the Constitution, whereas it is only $7 \%$ of participants who indicated that the matter will be resolved as demonstrated in Figure 5.

On this question, a significant majority (93\%) of the participants shared an idea that the replacement of Sepedi with Sesotho sa Leboa will not add value to this kind of onomastic problem. Having noted that the speakers of the language under scrutiny are divided into two groups, it is, however, clear based on this response that almost all the participants predict that the quarrels are still going to continue. Another critical interpretation of this response may be that the participants feel that the matter has been going on for a very long time, for 23 years, without any proper intervention from the relevant language authorities in resolving the matter under debate.
Earlier on Likert Statement 3, the participants strongly agreed that because of ethnic pride and the misuse of political powers and influnce, the onomastic controversy of Sepedi and Sesotho sa Leboa will not end any time soon. It can, therefore, be observed that there is a clear correlation between the attitudes recorded in Table 3 (Statement 3) and those recorded in Statement 4 as well as the $93 \%$ who indicated agreement in this question. On this question, it is important to point out that the issue of ethnic pride is not only directed to those who have political powers and influnece, it also touches on the L1 speakers of the language.

Moreover, it is fair to mention that the participants in Table 5 (Statement 5) strongly agreed that the language under research should be renamed with a neutral name that will not be associated with a particular ethnic group as well as with the previous regime, so as to ensure that the language name becomes more inclusive and unpolitical, not exclusive and political.

\section{For these arguments, P28 shared that:}

'[T]he argument of Sepedi and Sesotho sa Leboa as language names has been going on for quite some time with no clarity and decisive measures from the relevant parties (Constitution, Pan South African Language Board, Sesotho sa Leboa National Language Board and the Sesotho sa Leboa National Lexicography Unit). In my honest opinion, I personally think a new name may resolve this problem. However, relevant stakeholders should be brought on board during the composition and suggestions of the new name.' (P28)

In addition to this submisison, P62 articulated that:

' $[I] \mathrm{t}$ is important for people to note that although there is a strong opinion that Sepedi is not the appropriate term to serve as the name of the standard language held by the speakers of the other dialects, there is also a reasonable case for those who support Sepedi as the righful name of the language.' (P62)

It can be reasoned from the above-quoted participants that the issue of Sepedi and Sesotho sa Leboa (Northern Sotho)

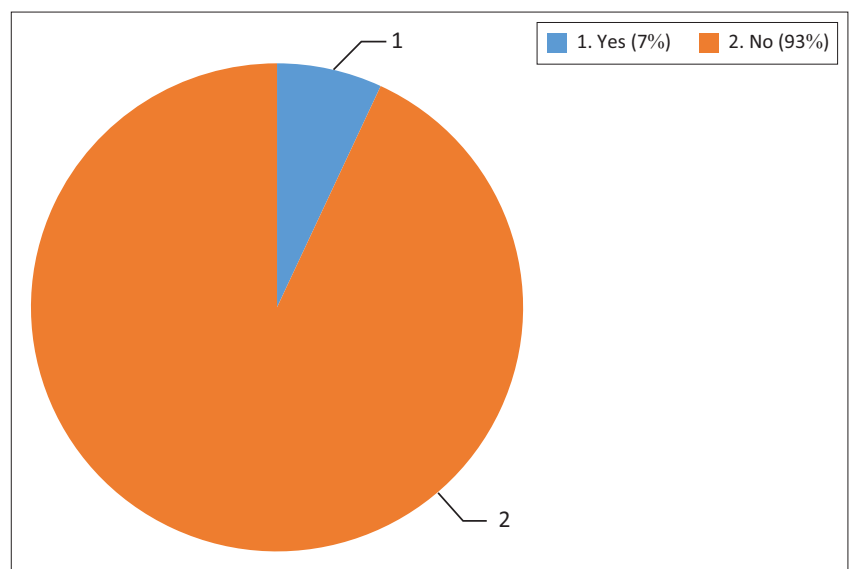

FIGURE 5: Constitutional implementation. 
language names is considered an identity issue. The issue under debate is also emotional to an extent that the participants held the view that maybe the mentioned two different language names should just be replaced because they cause divisions amongst the L1 speakers. Another reason that is detected from the above excerptions is that it is also difficult for the researchers to identify a language name between the mentioned two that the partcipants support and are in full favour of. Nonetheless, the views of $7 \%$ of those who were of the view that the replacement of Sepedi with Sesotho sa Leboa will resolve the matter cannot be disregarded. For this reason, P220 said that:

' $[I] \mathrm{t}$ will not - unless and until people understand that the replacement of Sepedi (combination of a number of dialects) be confused with Sesotho sa Leboa (originating from a direction "North"). That is, people must realise that Sesotho sa Leboa has no bearing on a linguistic society. In essense, it does not provide a clear background of the speakers of the language. It is just a mere generic term that is given meaning by those who are against Sepedi as the name of the standard official language.' (P220)

Another Participant (239) emphasised that:

'[T]he main issue to be addressed in this onomastic confusion is understanding. Speakers from both sides need to be taught to understand the processes that are applied in language standardisation. For example, isiXhosa has dialects and what is considered the standard isiXhosa is not a full representation of all the dialects. Other dialects were heavily stigmatised during the standardisation period but you will never find them arguing that I am not isiXhosa - I am Bhaca or Hlubi.' (P239)

Equally important, the above-mentioned quotations also need to be taken into consideration. The researchers concur with them that proper understanding should be inculcated so that the final product will be accompanied with knowledge.

\section{RQ6: Onomastically speaking, do you think that the renaming of this language can bring unity and harmony to the first language speakers of the language under the study? Motivate your answer}

Because the study aimed to resolve the current onomastic dilemma under scrutiny, it is crucial to pay more attention to this question, not that other questions were not prioritised. In this quest, the researchers submit that the issue of renaming of the language under onomastic debate should not be determined by the majority rule. It is advisable to critique the justifications that will accompany each response in order to avoid the issue of the majority rule. The reason for this conception is that what is deemed to be right by the majority may be completely right or wrong when applying and following the onomastic principles of naming and vice versa. The gist of the matter in this case is to be guided by the justifications that follow the participants' final decision.

A significant majority (79\%) of the participants opined that it is of good interest for the language to be renamed. This kind of response suggests that it is not only those participants who perceive Sepedi as the relevant name of the language or even those who view Sesotho sa Leboa as the relevant name of the language, both shared a common perspective of getting rid of the current language names. On the other hand, $21 \%$ of participants held a different point of view that there is no need for the language to be renamed as demonstrated in Figure 6 .

It is somehow surprising to see that the participants felt that renaming the language would bring peace, unity and harmony to the entire speech communities of the language under investigation. This response indirectly reveals that the participants agreed that the speakers of this language were currently divided because of the Sepedi language name that appears in Section 6 (1) of the South African Constitution of 1996. Reasonably, other speakers are of the view that the Sepedi name does not deserve to be given any official recognition, whereas other speakers hold the opposite view that the Sesotho sa Leboa name does not also deserve official recognition.

The participants have been consistent in rejecting both Sepedi and Sesotho sa Leboa language names. It is evident from the responses they provided in the Likert scale statements that the participants were consistent. In Likert Statement 3 (Table 3), a high mean score of 4.7 was recorded which strongly agreed with the interpretation that the onomastic controversy surrounding Sepedi and Sesotho sa Leboa as language names may not end any time soon because of the influence of ethnic pride and the misuse of political powers.

A participant who was in favour and support of a new neutral language name, P220, articulated that:

' $[T]$ hose of us who love this language are hurt to live with this kind of confusion that we do not know when it will end. In my honest opinion, both Sepedi and Sesotho sa Leboa should just be obliterated as if they never existed. If we get an inclusive name, speakers of all dialects will be united, as this will also eliminate social injustices on inferior dialects. It is not fair for the people who originate from Ga-Sekhukhune to be given special recognition at the expense of the people from other dialects and ethnic groups.' (P220)

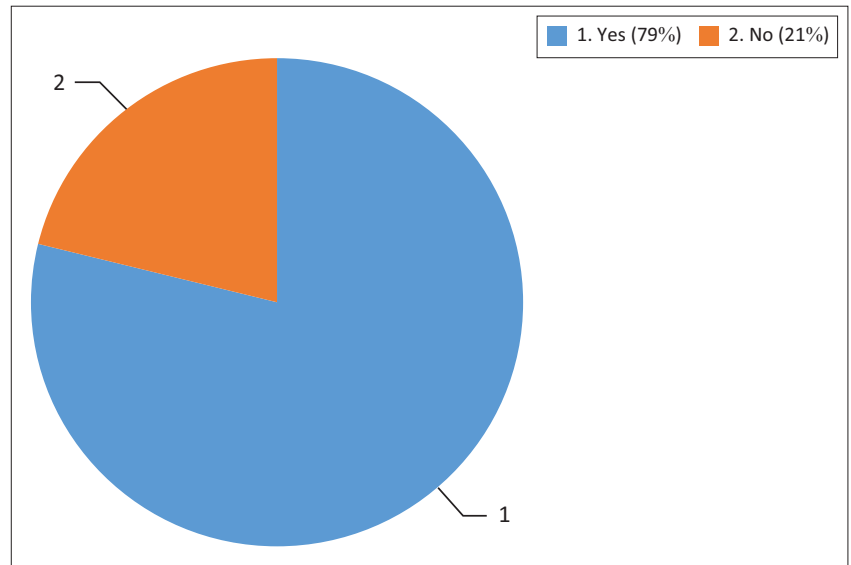

FIGURE 6: The renaming of the language under onomastic scrutiny. 
P2 in this regard emphasised that:

'[T]o end the current controversy that serious affects our identity as the speakers of this language, there is a need of a new name. However, people need to be educated about the eradication of the current names, so that they can welcome and accept the new name which I sincerely hope should be clear and common since the current names are full of politics that I cannot stomach anymore.' (P2)

Another Participant (9) who held a similar ideology proposed that:

' $[A]$ s I have already indicated, the debate of Sepedi and Sesotho sa Leboa has been going on for a very long time and some of us cannot stomach it anymore. I personally think that the new name will be far much better; even if it can still be attacked with criticism, the situation will be better than the current one, especially if the first language speakers will be given an opportunity to submit their views on the new name of the language.' (P9)

Lastly, the consequences that follow dual naming of this language are elucidated by P36 who in this regard indicated that:

'[N]ow, much attention is paid to the debate of whether the language should be Sepedi or Sesotho sa Leboa, rather than the efforts for the development of the language. As one of the speakers of this language, I am also concerned and frustrated by the use of both Sepedi and Sesotho sa Leboa as official languages. However, it cannot be right if the attention is now on the politics of language names, rather than on the linguistic development of the language.' (P36)

It is interesting to note that the above-quoted participants all reasoned in a social and academic manner. It is not that they do not like the current names, it is quite clear that each language name has sufficient support from its group. It is praiseworthy that they are willing to swallow their ethnic pride and were in full support of the renaming of the language. It is, however, not known whether the new language name will indeed bring peace, unity and harmony to the L1 speakers.

\section{Recapitulation of the main findings Unconstitutional replacement of the name Sesotho sa Leboa with Sepedi in the Constitution, 1996}

The participants in this study opined that the decision of replacing Sesotho sa Leboa with Sepedi in Section 6 (1) of the Constitution of South Africa was unconstitutional. The reason for this is that there are no proper justifications provided for this kind of status planning decision. Furthermore, it is observed that the L1 speakers of the language under onomastic investigation were not consulted. Thus, the process lacked transparency and violated the linguistic rights of the concerned speech community. It needs to be emphasised that this kind of violation does not suit a democratic country such as the Republic of South Africa.

\section{The rejection of Sepedi as a symbol of identity}

The findings of the study encapsulate that the L1 speakers do not accept Sepedi as a symbol of their identity. Emanating from an onomastic perspective, it is vital to mention that language names reflect identity. Therefore, it is equally important to remind ourselves that the Sepedi language name is listed as one of the 11 official languages of South Africa.

\section{Sesotho sa Leboa (Northern Sotho) as a colonial name}

In this study, a significant majority of the participants who rejected Sesotho sa Leboa as a language name reported that language names such as Northern Sotho (Sesotho sa Leboa), Southern Sotho (Sesotho) and Western Sotho (Setswana) were all created during the colonial period as these English names suited the administrative system of the Apartheid regime. The participants in this regard refused to be identified by a language name that came as an imposition from the outside. The participants advocated that the mentioned language names are associated with the previous regime, which has left an unpalatable history to the people of South Africa.

\section{The replacement of both Sepedi and Sesotho sa Leboa language names with a more inclusive and neutral name}

The language under study is characterised as a language of many dialects. An overwhelming majority of participants in this study stated that both Sepedi and Sesotho sa Leboa should be replaced with a new language name and it is anticipated that the new name will bring peace, unity and harmony to the entire speech community. According to the researchers, it can be interpreted that the participants reached a compromise that they have to do away with the current names that cause immense confusion to the speakers of this language and also to the people of this country. The reason for this submission is that the participants articulated that the use of both Sepedi and Sesotho sa Leboa (Northern Sotho) as official languages has been going on for a very long time and no practical measures have been taken by the relevant language authorities to resolve the matter. It is, however, crucial to note that the participants advised that the new language name should be inclusive as much as possible. They further opined that it should not be associated with any dialectal classification, as is the present case with the Sepedi language name that is simultaneously the name of the dialect. It was proposed that the new language name should also be neutral, free from politics and confusion, to avoid a third language name in the official documentation. ${ }^{2}$

2.Yes, if the issue of the Sepedi and Sesotho sa Leboa (Northern Sotho) language names is to be addressed, it should happen with proper consultation of the LI speakers within the relevant communication. The process of involving L1 speakers should happen on the most representative level including communities, traditional leaders, schools, students in tertiary institutions and language authorities at local leaders, schools, students in tertiary institutions and language authorities at loca and government level, for instance. Should the renaming process be driven by relevant language authorities (The National Department of Arts and Culture, The South African Geographical Names Council, PanSALB, Sesotho sa Leboa Nationa Language Body and Provincial Language Council), the neutral name may satisfy significant majority of the speakers of the language. The L1 speakers of including the Departments of Basic and Higher Education and Training should also be involved in the discussions. 


\section{The complete rejection of Sepedi and Sesotho sa Leboa (Northern Sotho) names by the onomastic principles}

The literature consulted in this study proves that both Sepedi and Sesotho sa Leboa do not meet the onomastic criteria of being used as official standard language names. The textual findings were also supported by a significant majority of the participants who articulated that they cannot stomach the controversy surrounding Sepedi and Sesotho sa Leboa as one and the same. They reported that it is in the best interest of the concerned speech community to have a new language name that will serve as the new standard official language name. In justification of the language name, they presented that there is a competent body that deals with the standardisation of geographical names as an attempt to reverse the onomastic subjugation created by the previous regime.

\section{Sepedi and Sesotho sa Leboa (Northern Sotho) language names and decoloniality}

The findings of the article record both Sepedi and Sesotho sa Leboa (Northern Sotho) as two different language names that have been used and are still used to refer to one and the same official language. This has some interrelatedness with colonialism. In a more practical sense, the two language names are considered instructive names in this article. This means that they were both imposed on the L1 speakers of the language. This is the main reason why these names are not entirely accepted by the speakers of the language. It is, therefore, relevant for the researchers to submit that the views and perspectives of the participants on renaming the language under debate be looked into in ensuring that the relationship between the name-giver and the namerecipient is healthy. The linguistic rights of the L1 speakers should be respected, not violated.

\section{Conclusion}

The onomastic controversy of Sepedi and Sesotho sa Leboa language names has been going on for the past 23 years, after the promulgation of the new South African Constitution in 1996. The study aimed to look into the possibility of renaming the language under onomastic scrutiny with the hope of bringing peace, unity and solidarity amongst the L1 speakers of this language. Most participants shared that the matter has been ongoing for quite some time without proper and empirical interventions from the relevant stakeholders. It is against this background that they agreed that the language should be renamed with a new neutral name that cannot in any way be associated or linked with any dialectal classification, ethnic group or political interference. The recommendation came after both the language names were found to be onomastically questionable when they serve as the name of the standard official language.

\section{Acknowledgements}

The authors would like to express their sincere gratitude and appreciation to all the universities, government departments and language authorities for allowing the researcher to administer survey questionnaires and interview their staff members during normal working hours.

\section{Competing interests}

The authors declare that they do not have any financial or personal relationships that may have inappropriately influenced them in writing this article.

\section{Authors' contributions}

The content of this article is partly based on the $\mathrm{PhD}$ thesis of T.J.R. (2019) that was completed under the supervision of E.B.Z. T.J.R. drafted the article whilst E.B.Z. revised it, before both of them could finalise it.

\section{Ethical considerations}

This onomastic study has received written approval from the University of the Witwatersrand Human Research Ethics Committee (Non-Medical) R14/49 and the protocol number is H17/06/46. Copies of the approval letters can be obtained from the primary researcher. Because the study targeted human participants from other South African universities and government departments, it is worthy to point out that ethical approval was also obtained from all the universities, organisations and relevant language authorities where the research was conducted.

\section{Funding information}

The authors would like to acknowledge the University Development Capacity Grant (TUT), funded by the Department of Higher Education (DHET) for financial support and stability. Equally important is the financial assistance of the National Institute for the Humanities and Social Sciences (NIHSS), in collaboration with the South African Humanities Deans Association (SAHUDA), which is hereby acknowledged.

\section{Data availability}

The data that support the findings of this study are openly available in the University of the Witwatersrand, Johannesburg Digital Open Repository.

\section{Disclaimer}

The views and opinions expressed in this article are those of the authors and do not necessarily reflect the official policy or position of any affiliated agency of the authors.

\section{References}

Ivankova, N.V., Creswell, J.W. \& Plano Clark, V.L., 2016, 'Foundations and approaches to mixed methods research', in K. Maree (ed.), First steps in research, pp. 333-346 Van Schaik, Pretoria.

Kadmon, N., 2013, 'Toponym and geopolitics: The political use - and misuse - of geographical names', The Cartographic Journal 41(2), 85-87. https://doi. org/10.1179/000870404X12897

Koopman, A., 2002, Zulu names, University of Natal Press, Pietermaritzburg. 
Kretzer, M.M., 2016, 'Variations of overt and covert language practices of educators in the North West Province: Case study of the use of Setswana and Sesotho at primary and secondary schools', South African Journal of African Languages 36(1) primary and secondary schools', South African Journal of Afric

Machaba, M.A., 2004, 'Naming, identity and the African renaissance in a South African context', Unpublished PhD thesis, University of KwaZulu-Natal, Pietermaritzburg.

Makoni, S., Smitherman, G., Ball, A.F. \& Spears, A.K., 2005, Black linguistics: Language, society, and politics in Africa and the Americans, Routledge Taylor and Francis Group, London.

Manatsha, T.R., 2014, 'The politics of renaming "colonial" streets in Francistown', Botswana Historia 59(2), 269-288.

Mandende, I.P., 2009, 'A study of Tshivenda personal names', Unpublished DLitt et Phi thesis, University of South Africa, Pretoria.

Mashige, M.C., 2004, 'Identity, culture and contemporary South African poetry', Unpublished PhD thesis, Rand Afrikaans University, Johannesburg.

Mojela, V.M., 1997, The development of Bantu linguistics, NSOT300 Study Guide, University of the North, Pietersburg.

Mojela, V.M., 1999, 'Prestige terminology and its consequences in the development in Northern Sotho vocabulary', Unpublished DLitt et Phil thesis, University of South Africa, Pretoria.

Mojela, V.M., 2007, 'Polysemy and homonymy: Challenges relating to lexical entries in the Sesotho sa Leboa-English bilingual dictionary', Lexikos Journal 17, 433-439. https://doi.org/10.5788/17-0-537

Ndletyana, M., 2012, 'Changing place names in post-apartheid South Africa: Accounting for the unevenness', Social Dynamics: A Journal of African Studies 38(1), 90-94. https://doi.org/10.1080/02533952.2012.698949

Parliamentary Joint Constitutional Review Committee, 2011, Sesotho sa Leboa vs Sepedi, Government Printers, Pretoria.

Parliamentary Joint Constitutional Review Committee, 2016, Public submissions: Legal opinions, Government Printers, Pretoria.
Parliamentary Joint Constitutional Review Committee, 2017, Status of Sepedi, Sesotho sa Leboa, Khelovhedu \& Sign Language of South Africa \& Khoi, Nama \& San Languages: Pansalb, DAC \& CRL Rights Commission, Government Printers, Pretoria.

Parliamentary Joint Constitutional Review Committee, 2020, Language submissions: Overview, Government Printers, Pretoria.

Pfukwa, C., 2007, 'The function and significance of war names in the Zimbabwean armed conflict (1966-1979)', Unpublished PhD thesis, University of South Africa, Pretoria.

Rakgogo, T.J., 2016, 'A sociolinguistic perspective of first language speakers from the selected South African universities', Unpublished Master's dissertation, Tshwane University of Technology, Pretoria.

Rakgogo, T.J., 2019, 'Investigating the onomastic principles of naming an official language: The case of the Sepedi and Sesotho sa Leboa (Northern Sotho) language names', Unpublished PhD thesis, University of the Witwatersrand, Johannesburg.

Rakgogo, T.J. \& Van Huyssteen, L., 2018, 'Exploring the Northern Sotho language name discrepancies in informative documentation and among first language speakers', South African Journal of African Languages 38(1), 79-86. https://doi.org/10.1080/ 02572117.2019.1618015

Rakgogo, T.J. \& Van Huyssteen, L., 2019, 'A constitutional language name, lost in translation and its impact on the identity of the first language speakers', South African Journal of African Languages 39(2), 165-174.

Republic of South Africa, 1993, Interim constitution of the Republic of South Africa, Government Printers, Pretoria.

Republic of South Africa, 1996, Final constitution of the Republic of South Africa Government Printers, Pretoria.

South African Geographical Names Council Act, No. 118 of 1998, Government Printers, Pretoria.

Van Dijk, T.A, 1995, 'Aim of critical discourse analysis', Japanese Discourse 1(1), 18-20. https://doi.org/10.5565/rev/athenea.22

Wodak, R., 2001, 'The discourse-historical approach', in R. Wodak \& M. Meyer (eds.), Methods of CDA, pp. 81-115, Sage, London. 